\title{
Surgical Treatment of Rectal Prolapse: A 10-Year Experience at a Single Institution
}

\author{
Aeris Jane D. Nacion, M.D. ${ }^{1}$, Youn Young Park, M.D. ${ }^{2}$, Ho Seung Kim, M.D., Ph.D. ${ }^{3}$, Seung Yoon Yang, M.D. ${ }^{3}$, \\ Nam Kyu Kim, M.D., Ph.D., FACS, FASCRS 3 \\ 'Department of Surgery, Eastern Visayas Regional Medical Center, Tacloban, Philippines, ²Department of Surgery, Uijeongbu St. Mary's Hospital, College of \\ Medicine, The Catholic University of Korea, ${ }^{3}$ Division of Colorectal Surgery, Department of Surgery, Yonsei University College of Medicine, Seoul, Korea
}

Purpose: Despite the plethora of surgical options, there is no consensus regarding the best treatment for rectal prolapse. This study is aimed at evaluating our experience with its treatment and outcomes.

Methods: We retrospectively reviewed rectal prolapse patients' characteristics, clinical presentation, surgical procedure, average length of hospital stay, morbidity, mortality, and recurrence over a 10 year period at our institution.

Results: A total of 46 patients underwent rectal prolapse repair at our institution over a 10 year period. Of the 39 patients with primary rectal prolapse, 18 patients had an abdominal procedure, while 21 patients underwent a perineal approach. Operative duration was significantly longer in abdominal procedures, of which 16 cases were performed laparoscopically. Length of hospital stay and recurrence were not statistically significant between the 2 groups. In patients with recurrent rectal prolapse, more than $80 \%$ of the initial surgeries were done using the perineal approach. An abdominal approach was utilized in the management of $75 \%$ of recurrences.

Conclusion: An abdominal repair may be preferable in the treatment of recurrent rectal prolapse. Minimally invasive techniques may be feasible and can provide a safe alternative to perineal procedures in elderly patients.

Keywords: Procidentia, Prolapse, Rectal prolapse, Rectal diseases, Rectum
Received May 29, 2019

Revised September 9, 2019

Accepted September 16, 2019

Corresponding author

Nam Kyu Kim

Division of Colorectal Surgery,

Department of Surgery, Yonsei

University College of Medicine, 50-1

Yonsei-ro, Seodaemun-gu, Seoul

03722, Korea

Tel: +82-02-2228-2117

Fax: +82-02-313-8289

E-mail: namkyuk@yuhs.ac

ORCID:

https://orcid.org/0000-0003-0639-5632

Oral presentation during the 51th Annual Meeting of the Korean Society of Coloproctology, Gwangju, South Korea (March 30-April 1, 2018).

Copyright $(2019$ The Journal of Minimally Invasive Surgery. All rights reserved.

\section{INTRODUCTION}

Rectal prolapse, or procidentia, is a debilitating disease that was first described in Ebers Papyrus, an Egyptian medical papyrus of herbal knowledge dating back to $1550 \mathrm{BC}{ }^{1}$. The protrusion of all rectal layers through the anal orifice, manifesting as concentric rings of rectal folds, serve as the hallmark of the disease. Complete rectal prolapse is the circumferential full thickness rectal wall protrusion beyond the anal canal. In contrast, partial rectal prolapse involves the protrusion of only the mucosa. ${ }^{2}$

Although estimated to occur in only $0.5 \%$ of the adult population, a myriad of surgical procedures exist to treat rectal prolapse. ${ }^{2,3}$ Despite the number of surgical options, there are still ongoing debates over whether an abdominal or a perineal approach is best, and up until the present, no consensus statement has been made regarding the best surgical treatment. ${ }^{1,4}$ Traditionally, perineal techniques, which are perceived to be 
associated with lower operative morbidity and mortality but high recurrence rates, have been recommended for medically unfit or elderly patients. Because a perineal approach can be performed under regional anesthesia, it is considered to be better tolerated compared to an abdominal procedure, thereby resulting in lesser pain and fewer complications. On the other hand, physically fit candidates have been recommended to undergo abdominal procedures, which are characterized to have lower recurrence rates than perineal operations. ${ }^{5}$

The advent of minimally invasive techniques has allowed abdominal procedures to be performed with the same safety and tolerance as perineal procedures, consequently challenging conventional knowledge regarding differences in recurrence and reoperative rates. ${ }^{1}$ The PROSPER trial, the largest randomized controlled trial for rectal prolapse by Senapati et al., revealed no significant difference in recurrence rates among rectal prolapse procedures. ${ }^{4}$ Likewise, Tou et al. in their Cochrane review concluded that apart from the agreement that surgery is the best strategy for rectal prolapse treatment, differences among surgical techniques are difficult to refute or ascertain due to the diversity of the studies and the methodological deficiencies of the included trials. ${ }^{6}$

At present, literature is bereft of clinical evidence assessing the reliabiility, effectiveness, and appropriateness of each rectal prolapse repair technique. ${ }^{6,7}$ In fact, treatment is individualized, and the surgical approach is tailored primarily according to the patient's age, physical condition, bowel function, and surgeon's preference. ${ }^{5}$ This study aims to review our experience in the management of rectal prolapse during the last 10 years in order to evaluate clinical and surgical outcomes of both minimally invasive procedures and other rectal prolapse repair techniques.

\section{MATERIALS AND METHODS}

Between January 2006 and January 2016, we retrospectively collected data on all patients diagnosed with full thickness rectal prolapse who underwent surgical repair at Severance Hospital, Yonsei University Health System. Prior to the commencement of the study, approval from the Institutional Review Board (IRB) of Severance Hospital was obtained. Given the retrospective nature of the study, the prerequisite of acquiring an informed consent was waived by the IRB. All patients with full thickness rectal prolapse were included in the study. Patients with prolapsed internal hemorrhoids and mucosal prolapse were excluded. All surgical procedures were performed by members of the consultant staff of the Division of Colorectal Surgery, and all patients during that period underwent surgical prolapse repair in an elective setting. The choice of surgical technique was left to the discretion of the attending colorectal surgeon; however, a perineal approach was preferred for medically unfit and elderly patients.

Preoperative patient data pertaining to patient age, sex, initial symptomatology, American Society of Anesthesiologists (ASA) grade, and body mass index (BMI) were collected. Operative data included type of surgical procedure performed, duration of operation, and operative blood loss. Postoperative data included length of postoperative hospital stay, complications, and recurrence. Rectal prolapse was defined as the circumferential, full-thickness protrusion of the rectal wall through the anal orifice. On the other hand, recurrence is a rectal prolapse in a patient who had previously undergone an operative intervention. The time of recurrence for rectal prolapse was calculated from the time of the initial operation until the time of clinical presentation of recurrent prolapse (Fig. 1).

Data were analyzed using IBM SPSS Statistics version 22.0. Results are presented as percentages for categorical outcomes, and as medians and interquartile ranges $\left(\mathrm{Q} 1 \sim \mathrm{Q}^{3}\right)$ for continuous outcomes. A $p$-value $<0.05$ was considered statistically significant.

\section{RESULTS}

\section{Patient characteristics}

A total of 46 patients with rectal prolapse were included in the analysis. The preoperative and intraoperative characterictics of all patients are described in Table 1. The median age was 65.2 years old (range, 19 87 years old), with more than half represented by females (65.2\%). On initial assessment,

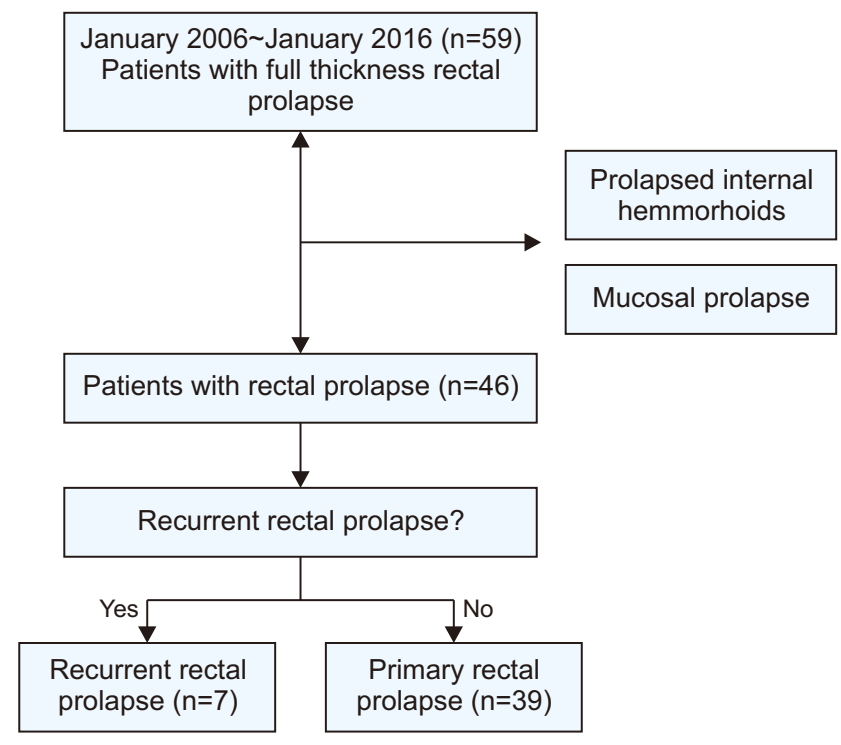

Fig. 1. Study flowchart. 
majority presented with a protruding mass $(n=43,93.5 \%)$, while the rest $(n=3,6.5 \%)$ presented with fecal incontinence. The mean BMI was $23.0 \mathrm{~kg} / \mathrm{m}^{2}$ (17.0 30.6). Among the $46 \mathrm{pa}-$ tients, about a third $(\mathrm{n}=14,30.5 \%)$ have an American Society of Anaesthesiologists (ASA) physical status classification grade of equal and more than III. Thirty-nine (84.8\%) patients had primary rectal prolapse, while $7(15.2 \%)$ presented with recurrent prolapse.

Table 2 describes the characteristics of patients with primary rectal prolapse. Of the 39 patients with primary rectal prolapse, 18 patients had an abdominal procedure, while 21 patients underwent a perineal approach for rectal prolapse repair. Patients who underwent a perineal repair tended to be older than those who had an abdominal procedure; however, this was not statistically significant.

\section{Clinical and surgical outcomes of primary rectal prolapse patients}

Of the 18 patients who had an abdominal procedure, 16 (88.9\%) were done with the assistance of laparoscopy. Only two patients in our study underwent open abdominal procedures. One patient had to undergo open anterior resection because of a concomitant vaginal prolapse which required referral to gynecology, while another patient presented with dense intraoperative adhesions, necessitating conversion to

Table 1. Overall patient characteristics

\begin{tabular}{|cc}
\hline \multicolumn{1}{|c}{ Characteristics } & $(\mathbf{n}=46)$ \\
\hline Age, mean $\pm S D, y$ & $65.2 \pm 15.7$ \\
Sex, $\mathbf{n}(\%)$ & $16(34.8)$ \\
Male & $30(65.2)$ \\
Female & \\
ASA, $n(\%)$ & $19(41.3)$ \\
I & $13(28.3)$ \\
II & $13(28.3)$ \\
III & $1(2.2)$ \\
IV & $23.0 \pm 3.6$ \\
BMI, mean $\pm S D$, kg/m \\
Clinical presentation & \\
Protruding mass & $43(93.5)$ \\
Fecal incontinence & $3(6.5)$ \\
Type of rectal prolapse & \\
Primary rectal prolapse & $39(84.7)$ \\
Recurrent rectal prolapse & $7(15.3)$ \\
\hline
\end{tabular}

open surgery. On the other hand, 21 primary rectal prolapse patients underwent perineal repair.

Operative duration was significantly longer in abdominal procedures compared to the perineal approach. There were more minor postoperative complications in the abdominal approach; however this was not statistically significant. The length of hospital stay was not statistically significant between the 2 groups. There were 2 recurrences after an abdominal repair; while there were 3 recurrences after a perineal pro-

Table 2. Characteristics of primary rectal prolapse patients

\begin{tabular}{lrrc|}
\hline \multicolumn{1}{|c}{ Characteristics } & $\begin{array}{c}\text { Abdominal } \\
(\mathbf{n}=18)\end{array}$ & $\begin{array}{c}\text { Perineal } \\
(\mathbf{n}=21)\end{array}$ & $p$ \\
\hline Age, mean $\pm S D, y$ & $61.9 \pm 12.2$ & $65.5 \pm 19.7$ & 0.508 \\
$\begin{array}{l}\text { Sex, } \mathrm{n}(\%) \\
\quad \text { Male }\end{array}$ & $8(44.4)$ & $8(38.1)$ & \\
$\quad$ Female & $10(55.6)$ & $13(61.9)$ & \\
ASA, $n(\%)$ & & & 0.752 \\
I & $9(50.0)$ & $8(38.1)$ & \\
II & $4(22.2)$ & $7(33.3)$ & \\
III & $4(22.2)$ & $6(28.6)$ & \\
IV & $1(5.6)$ & $0(0.0)$ & \\
BMI, mean $\pm S D, \mathrm{~kg} / \mathrm{m}^{2}$ & $23.0 \pm 3.9$ & $22.5 \pm 3.2$ & 0.657 \\
\hline
\end{tabular}

Table 3. Postoperative outcomes of primary rectal prolapse patients

\begin{tabular}{|c|c|c|c|}
\hline Characteristics & $\begin{array}{l}\text { Abdominal } \\
(\mathrm{n}=18)\end{array}$ & $\begin{array}{l}\text { Perineal } \\
(\mathrm{n}=21)\end{array}$ & $p$ \\
\hline Operation method, n (\%) & & & $<0.001$ \\
\hline Open & $2(11.1)$ & $21(100)$ & \\
\hline Laparoscopic & $16(88.9)$ & $0(0)$ & \\
\hline $\begin{array}{l}\text { Operation time, } \\
\text { mean } \pm S D, \mathrm{~kg} / \mathrm{m}^{2}\end{array}$ & $181.2 \pm 73.4$ & $71.2 \pm 35.3$ & $<0.001$ \\
\hline Blood loss, mean $\pm S D$, ml & $10.8 \pm 22.5$ & $18.8 \pm 72.9$ & 0.638 \\
\hline $\begin{array}{l}\text { Postoperative } \\
\text { complications, n (\%) }\end{array}$ & & & 0.21 \\
\hline Urinary tract infection & $1(5.0)$ & $0(0)$ & \\
\hline Neurologic bladder & $1(5.0)$ & $0(0)$ & \\
\hline Recurrent & & & $>0.999$ \\
\hline Yes & $2(10.0)$ & $3(13.0)$ & \\
\hline No & $16(90.0)$ & $18(87.0)$ & \\
\hline $\begin{array}{l}\text { Length of hospital stay, } \\
\text { mean } \pm S D \text {, d }\end{array}$ & $7.8 \pm 5.9$ & $6.8 \pm 4.2$ & 0.533 \\
\hline
\end{tabular}


cedure. The average length of time to recurrence was 19.5 months. Table 3 provides the postoperative outcomes of $\mathrm{pa}^{-}$

Table 4. Characteristics of patients with recurrent rectal prolapse

\begin{tabular}{lc}
\hline \multicolumn{1}{c}{ Characteristics } & $(\mathbf{n}=12)$ \\
\hline Age, mean $\pm S D$, years & $66.4 \pm 4.7$ \\
Sex, $\mathbf{n}(\%)$ & \\
Female & $10(83.3)$ \\
Male & $2(16.4)$ \\
BMI, mean $\pm S D, \mathrm{~kg} / \mathrm{m}^{2}$ & $23.4 \pm 1.1$ \\
Initial Surgery & \\
Abdominal approach & $2(16.7)$ \\
Perineal approach & $10(83.3)$ \\
Second Surgery & \\
Abdominal approach & $9(75)$ \\
Perineal approach & $3(25)$ \\
Surgical Outcomes & $(\mathrm{n}=5)$ \\
Operative time (minutes) & $163.8 \pm 43.9$ \\
Blood loss (ml) & minimal \\
Hospital stay (days) & $13.6 \pm 6.4$ \\
\hline
\end{tabular}

tients with primary rectal prolapse.

\section{Recurrent rectal prolapse}

There were 12 patients with recurrent rectal prolapse (Table 4). These patients included those who presented initially as recurrent rectal prolapse at our outpatient clinics and those who had recurrence after undergoing initial rectal prolapse repair at our hospital. For patients with recurrent rectal prolapse, more than $80 \%$ of initial surgeries were done by the perineal approach. An abdominal repair was utilized in $75 \%$ of cases with rectal prolapse recurrence (second surgery). For the 5 patients who experienced rectal prolapse recurrence after undergoing initial repair at our institution, mean operative duration was 163 minutes with minimal blood loss and an average hospital stay of 13 days. There were no recurrences after operative treatment of recurrent rectal prolapse. Fig. 2 provides the diagram of the types of repair given to our 46 patients in a 10 year period.

\section{DISCUSSION}

Our institution has performed several procedures for the repair of rectal prolapse over the last ten years. At the turn of the decade, there has been an increasing trend towards the

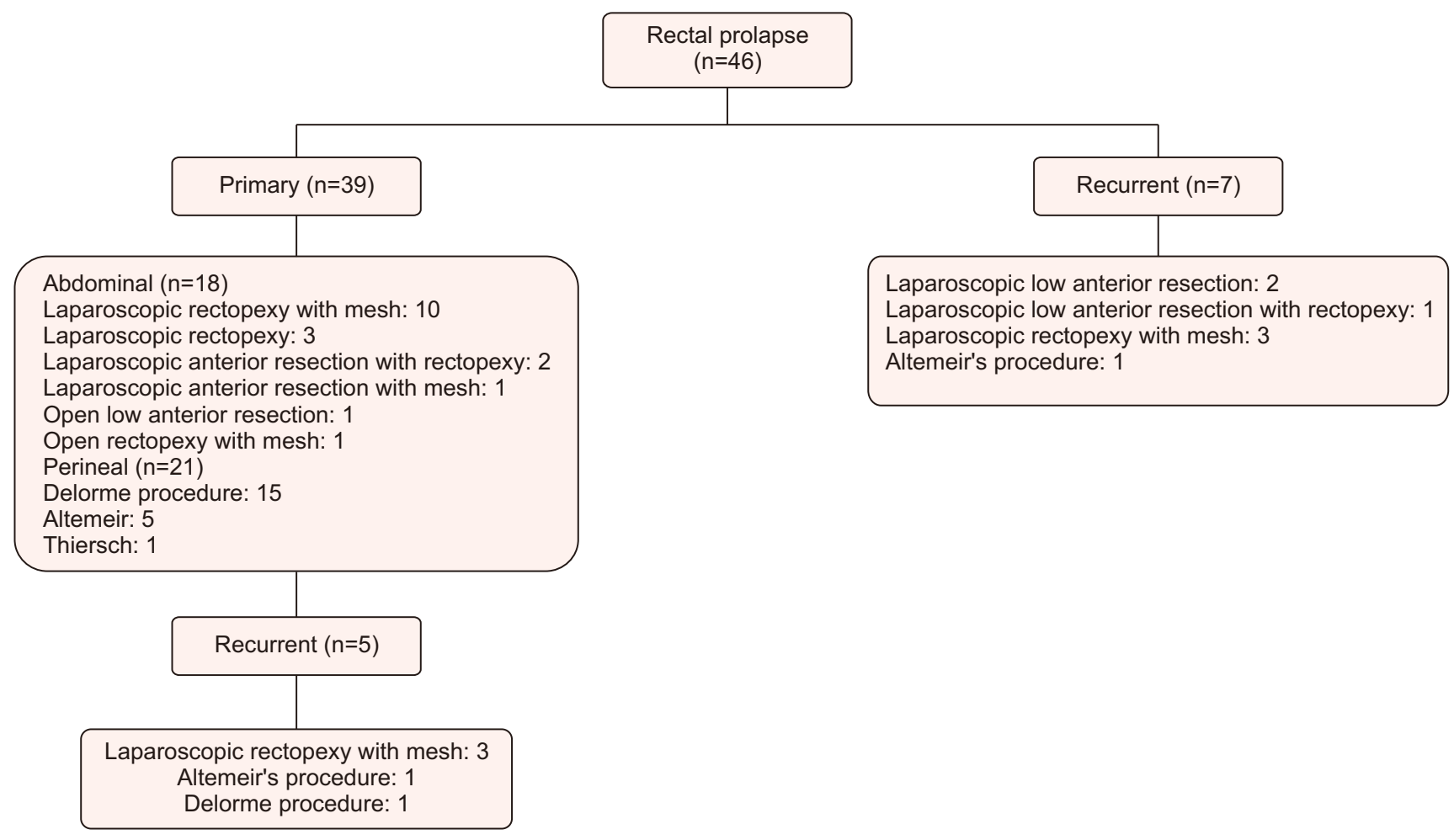

Fig. 2. Types of rectal prolapse repair performed on the 46 patients. 
laparoscopic approach for repair and a simultaneous reduction in the use of perineal procedures. These findings are reflective of the growing adaptation of the minimally invasive approach to rectal prolapse repair, which is associated with faster recovery, shorter hospital stay, and improved pain control. ${ }^{8,9}$

Regarding the relationship between sex and incidence of rectal prolapse, the findings in the current study stand in contrast to previously reported results in Korean scientific literature, which stipulate similar incidence rates in men and women. ${ }^{10,11}$ In line with Western studies, our findings revealed a higher incidence in females $(n=26,61.9 \%)$ and in the elderly population. ${ }^{8,12}$ Interestingly, the Korean males in the present study belong to older age groups, with majority older than 45 years of age. These findings are contrary to those reported in literature, which assert that the age of incidence among males is less than 40 years old. 8 ,12 Lee et al. propounded that the differences in Korean and western populations may be due to lifestyle, with the tendency to strain during defecation as the main reason. ${ }^{11}$ Since most of the studies on rectal prolapse are drawn from single center institutions, a population-based study is imperative to gain more insight regarding the incidence of rectal prolapse in South Korea.

Recurrence is of critical concern in the management of rectal prolapse, which has been reported to be as high as 30\% in patients after surgical repair. ${ }^{43}$ In contrast to the traditional view that that perineal procedures are associated with high recurrence rates, the present study has shown that recurrence rates between perineal versus the abdominal approach were not statistically significant. Additionally, the perineal approach was commonly utilized for older patients. Our findings, therefore, reflect the conventional view that the perineal approach is more frequently recommended to elderly patients to obviate the need for general anesthesia and reduce complications. ${ }^{14}$ The abdominal procedure was also frequently used to repair rectal prolapse recurrence. These findings also conform to the conventional view that abdominal procedures are more durable and less likely to create recurrence; nevertheless, studies concerning the optimal approach to recurrent rectal prolapse repair have been conflicting. Steele et al. reported that there were significantly fewer recurrences among patients who underwent an abdominal repair for recurrent rectal prolapse than those who had a perineal procedure (15\% vs $37 \%)^{15}$. On the other hand, Williams et al. assert that a repeat perineal rectosigmoidectomy can be performed for recurrent rectal prolapse with minimal morbidity. ${ }^{16}$

In the present study, the choice of surgical approach was left to the discretion of the attending colorectal surgeon. The age, sex, and presence of $\mathrm{co}^{-}$-morbidities appear to have no bearing on the choice of surgical procedure, with patients in older age groups undergoing laparoscopic abdominal repair. Further- more, the laparoscopy-assisted approach appear to have minimal impact on the occurrence of morbidity and recurrences. These findings corroborate with the results of the PROSPER trial which showed no significant differences in terms of recurrence rates among rectal prolapse repair procedures. Although the PROSPER trial has been heavily criticized for being underpowered and being methodologically flawed, it was able to challenge the conventionally held belief that perineal procedures would result in higher recurrence compared to abdominal techniques. Moreover, the trial raised questions regarding selection bias, with perineal surgery being offered disproportionately to older, frail patients with less healthy tissues thereby predisposing them to higher recurrence. ${ }^{8}$

Our study brings to light the role of laparoscopy in the surgical management of rectal prolapse. The clinical practice guidelines for the treatment of rectal prolapse by the American Society of Colon and Rectal Surgeons (ASCRS) strongly recommend a minimally invasive approach by experienced colorectal surgeons due to lesser complications and comparable recurrence rates with open techniques. ${ }^{8}$ In addition, a recent meta-analysis by Caddedu et al. revealed that the safety and feasibility of laparoscopic rectopexy is comparable to the open technique in terms of recurrence. ${ }^{17}$ Our study affirms the aforementioned findings especially in terms of recurrence and morbidity; however, the use of laparoscopy in our abdominal procedures was also found to result in a longer operative time. This may be due to the steep learning curve for laparoscopic colorectal surgery, as studies have shown that 150 to 200 cases are needed to attain a significant level of proficiency. ${ }^{18-20}$ Corollary to the use of minimally invasive approach in rectal prolapse is its role of providing elderly patients of a better alternative to perineal procedures. Our study has shown that laparoscopy in older patients is feasible when done by a surgeon with considerable experience in minimally invasive techniques. Our findings are supported by recent study by a Gultekin et al. that showed no significant differences in terms of major complication and mortality rates between patients older than 70 years old and patients younger than 70 years of age. $^{21}$

The current study has several limitations that must be acknowledged in the interpretation of results. Since this is a retrospective study, uncontrollable biases, such as information and selection biases, may have been present. Variables that could have possibly influenced outcomes including surgeon operative experience were also not tested. In addition to the small sample size, our study did not allow for the evaluation of bowel function before and after surgery. These limitations preclude any definitive conclusion about the superiority of one technique over the other, even more when considering the heterogeneity of abdominal repair techniques. Despite these 
shortcomings, we endeavored, nonetheless, to provide an understanding of the changes of surgical techniques over time, to challenge the conventional knowledge of limiting abdominal procedures in young, healthy patients, and to call for a need of a population-based study in order to better manage our Korean patients.

In conclusion, an abdominal repair may be preferable in the treatment of recurrent rectal prolapse. The use of minimally invasive techniques in rectal prolapse repair is feasible and can provide a safe alternative to perineal procedures in elderly patients. In the future, a prospective study with a larger patient cohort is needed to validate our results.

\section{ORCID}

Aeris Jane D. Nacion, https://orcid.org/0000-0001-9324-4132 Youn Young Park, https://orcid.org/0000-0001-7724-1492 Ho Seung Kim, https://orcid.org/0000-0002-7378-0584 Seung Yoon Yang, https://orcid.org/0000-0001-8129-7712 Nam Kyu Kim, https://orcid.org/0000-0003-0639-5632

\section{AUTHORS' CONTRIBUTIONS}

Conceptualization: NKK. Formal analysis: AJDN. Methodology: YYP, HSK. Writing-original draft: AJDN, SYY. Review and editing: NKK, AJDN.

\section{CONFLICT OF INTEREST}

None.

\section{FUNDING}

None.

\section{ACKNOWLEDGMENTS}

None.

\section{REFERENCES}

1) Barfield LR. Perineal Approaches to Rectal Prolapse. Clin Colon Rectal Surg 2017;30:12-15.

2) Varma MG, Steele SR. Overview of rectal procidentia (rectal prolapse) [Internet]. Waltham, MA: UpToDate Inc.; c2017 [cited on 2017 February 7]. Available from: https://www.uptodate.com.

3) Cannon JA. Evaluation, Diagnosis, and Medical Management of Rectal Prolapse. Clin Colon Rectal Surg 2017;30:16-21.

4) Senapati A, Gray RG, Middleton LJ, et al. PROSPER: a randomised comparison of surgical treatments for rectal prolapse.
Colorectal Dis 2013;15:858-868.

5) Varma MG, Steele SR. Surgical approach to rectal procidentia (rectal prolapse) [Internet]. Waltham, MA: UpToDate Inc.; c2017 [cited on 2017 February 7]. Available from: https://www.uptodate. com.

6) Tou S, Brown SR, Nelson RL. Surgery for complete (fullthickness) rectal prolapse in adults. Cochrane Database Syst Rev 2015:CD001758. https://doi.org/10.1002/14651858.CD001758.pub3.

7) Bordeianou L, Hicks CW, Kaiser AM, Alavi K, Sudan R, Wise PE. Rectal prolapse: an overview of clinical features, diagnosis, and patient-specific management strategies. J Gastrointest Surg 2014; 18:1059-1069.

8) Bordeianou L, Paquette I, Johnson E, et al. Clinical Practice Guidelines for the Treatment of Rectal Prolapse. Dis Colon Rectum 2017;60:1121-1131.

9) Vogler SA. Rectal Prolapse. Dis Colon Rectum 2017;60:11321135.

10) Yoon SG. Rectal prolapse: review according to the personal experience. J Korean Soc Coloproctol 2011;27:107-113.

11) Lee JL, Yang SS, Park IJ, Yu CS, Kim JC. Comparison of abdominal and perineal procedures for complete rectal prolapse: an analysis of 104 patients. Ann Surg Treat Res 2014;86:249255.

12) Mills S. Rectal Prolapse. In: Beck DE, Wexner SD, Hull TL, et al., editors. The ASCRS Manual of Colon and Rectal Surgery. 2nd ed. New York, NY: Springer; 2014.

13) Hotouras A, Ribas Y, Zakeri S, et al. A systematic review of the literature on the surgical management of recurrent rectal prolapse. Colorectal Dis 2015;17:657-664.

14) Hori T, Yasukawa D, Machimoto T, et al. Surgical options for fullthickness rectal prolapse: current status and institutional choice. Ann Gastroenterol 2018;31:188-197.

15) Steele SR, Goetz LH, Minami S, Madoff RD, Mellgren AF, Parker SC. Management of recurrent rectal prolapse: surgical approach influences outcome. Dis Colon Rectum 2006;49:440-445.

16) Williams JG, Rothenberger DA, Madoff RD, Goldberg SM. Treatment of rectal prolapse in the elderly by perineal rectosigmoidectomy. Dis Colon Rectum 1992;35:830-834.

17) Cadeddu F, Sileri P, Grande M, De Luca E, Franceschilli L, Milito G. Focus on abdominal rectopexy for full-thickness rectal prolapse: meta-analysis of literature. Tech Coloproctol 2012;16:3753.

18) Rickert A, Kienle P. Laparoscopic surgery for rectal prolapse and pelvic floor disorders. World J Gastrointest Endosc 2015;7:10451054.

19) Miskovic D, Ni M, Wyles SM, Tekkis P, Hanna GB. Learning curve and case selection in laparoscopic colorectal surgery: systematic review and international multicenter analysis of 4852 cases. Dis Colon Rectum 2012;55:1300-1310.

20) Kayano H, Okuda J, Tanaka K, Kondo K, Tanigawa N. Evaluation 
of the learning curve in laparoscopic low anterior resection for rectal cancer. Surg Endosc 2011;25:2972-2979.

21) Gultekin FA, Wong MT, Podevin J, et al. Safety of laparoscopic ventral rectopexy in the elderly: results from a nationwide database. Dis Colon Rectum 2015;58:339-343. 